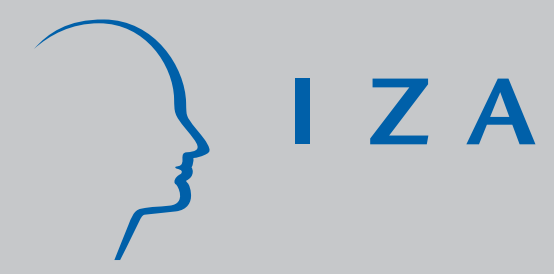

IZA DP No. 4034

Shattered Dreams:

The Effects of Changing the Pension System

Late in the Game

Andries de Grip

Maarten Lindeboom

Raymond Montizaan

February 2009 


\title{
Shattered Dreams: The Effects of Changing the Pension System Late in the Game
}

\author{
Andries de Grip \\ ROA, Maastricht University and IZA \\ Maarten Lindeboom \\ VU University Amsterdam, Tinbergen Institute, \\ HEB, Netspar and IZA \\ Raymond Montizaan \\ ROA, Maastricht University
}

Discussion Paper No. 4034

February 2009

\author{
IZA \\ P.O. Box 7240 \\ 53072 Bonn \\ Germany \\ Phone: +49-228-3894-0 \\ Fax: +49-228-3894-180 \\ E-mail: iza@iza.org
}

\begin{abstract}
Any opinions expressed here are those of the author(s) and not those of IZA. Research published in this series may include views on policy, but the institute itself takes no institutional policy positions.

The Institute for the Study of Labor (IZA) in Bonn is a local and virtual international research center and a place of communication between science, politics and business. IZA is an independent nonprofit organization supported by Deutsche Post Foundation. The center is associated with the University of Bonn and offers a stimulating research environment through its international network, workshops and conferences, data service, project support, research visits and doctoral program. IZA engages in (i) original and internationally competitive research in all fields of labor economics, (ii) development of policy concepts, and (iii) dissemination of research results and concepts to the interested public.
\end{abstract}

IZA Discussion Papers often represent preliminary work and are circulated to encourage discussion. Citation of such a paper should account for its provisional character. A revised version may be available directly from the author. 


\section{ABSTRACT \\ Shattered Dreams: The Effects of Changing the Pension System Late in the Game*}

This paper assesses the impact of a dramatic reform of the Dutch pension system on mental health, savings behavior and retirement expectations of workers nearing retirement age. The reform means that public sector workers born on January 1, 1950 or later face a substantial reduction in their pension rights while workers born before this threshold date may still retire under the old, more generous rules. We employ a unique matched survey and administrative data set comprising male public sector workers born in 1949 and 1950 and find strong ex ante effects on mental health for workers who are affected by the reform. This effect increases as birth dates approach the threshold date. Furthermore, the effects differ in accordance with worker characteristics. Finally, we find that the response of those affected by the reform is to work longer and to save more.

JEL Classification: $\quad$ I12, J08, J14, J26

Keywords: mental health, retirement, pension reform, causal effect

Corresponding author:

Maarten Lindeboom

VU University

Department of Economics

De Boelelaan 1105

1081 HV Amsterdam

The Netherlands

E-mail: mlindeboom@econ.vu.nl

\footnotetext{
* We gratefully acknowledge ABP for making the administrative data available. We acknowledge the comments and suggestions of seminar participants at Pompeu Fabra Barcelona, the University of Sheffield and the Netspar Theme conference on Health and Retirement. Special thanks go to Norma Coe, who suggested the title and for her excellent comments on an earlier draft of the paper.
} 


\section{Introduction}

This paper assesses the mental health effects of a change in the Dutch pension system. Prior to 2006, public sector workers in the Netherlands could retire at age 62 years and 3 months with a replacement rate of $70 \%$ of their average yearly earnings since $2002 .{ }^{1}$ As of 2006, those born before January 1, 1950 could continue to retire under the old rules, but for those born on or after January 1, 1950 the replacement rate is lowered to $64 \%$. These younger workers need to work an additional 1 year and 1 month to obtain the $70 \%$ replacement rate enjoyed by counterparts who may be just a few days, weeks or months older. Two years after the policy change, we compared the mental health of workers born in 1949 (turning 59 years old in 2008) and 1950 (turning 58 years old in 2008). We find strong effects from the exogenous change in the retirement system: depression rates among the 1950 cohort were about 40\% higher than among the 1949 cohort. To our knowledge, this is the first study to document large and persistent ex ante mental health effects from a change in a retirement system.

Our findings are relevant for a number of reasons. First, depression is a relatively common disorder, with prevalence rates of about $10 \%$ in the US, the UK and The Netherlands. Depression is among the leading causes of disability worldwide (WHO, 2006) and it is associated with heart disease, diabetes, some forms of cancer, and other diseases. Indeed, health care expenditures of depressed individuals are about four times higher than those of non-depressed individuals. In addition to these direct effects on health care costs, indirect costs from depression are substantial. Depression leads to lower productivity, workplace errors, faulty products, accidents, and increased absenteeism and disability insurance expenditures. In fact, in the last decade an increasing share of disability insurance expenditure in the western world is due to mental illnesses (OECD, 2008).

Second, our findings are relevant for public policy in the context of ageing. Most developed countries are currently encouraging prolonged working lives for older workers in order to mitigate the adverse effects of an aging population. Increasing labor force

\footnotetext{
${ }^{1}$ Until January 1, 2002, pension benefits were calculated using wage earnings in the year prior to retirement. Since 2002, pension benefits have been calculated using average annual earnings since 2002.
} 
participation rates among older workers improves the fiscal stability of pension systems. However, a natural question which has been largely overlooked by policy makers concerns the effect of later retirement on individual well-being and, in particular, on health. Adverse (or positive) effects from later retirement on post-retirement health not only influence individual well-being, but also directly affect health care costs at ages after retirement. Our finding of persistent ex ante health effects from changes in the retirement system suggests that post-retirement health worsens when individuals are induced to extend their working lives.

Third, following up on the second point, there is a recent and growing body of literature on the health effects of retirement. Cross-sectional analyses usually find that those who retire early have worse post-retirement health. Shan et al. (2005) compare mortality rates at later ages and find that post- 65 mortality rates are higher for those who retire early. Dave, et al. (2006) find that earlier retirement is associated with poor physical and mental health after retirement. It has been hypothesized that retirement in itself is a stressful event, or that retired people lose the physical and mental activity that is associated with work and/or that social networks associated with work decline. The policy implication of such findings indicates that increasing retirement age would lead to better individual health and well-being and may reduce the burden on (public) health care systems as well as on pension systems. Alternatively, it may be true that aspects of work (stress or job characteristics) worsen health, leading to positive effects from retirement and negative effects from continued work. These alternative mechanisms illustrate that it is difficult to infer causation from a direct comparison of the health status of early retirees with later retirees. Indeed, health may affect work and vice versa. Moreover, unobserved factors may confound the relationship between health and work.

Recent papers in this area have tried to circumvent this endogeneity problem by using an Instrumental Variable approach. Charles (2002) and Neumann (2007) use agespecific retirement incentives provided by the US social security system to capture changes in labor force participation that are unrelated to health. Similarly, Bound and Waidmann (2008) employ age-specific retirement incentives of the UK social security system to gauge the effect of retirement on health. Coe and Lindeboom (2008) use the availability of retirement windows as an instrument. All these studies confirm that the 
cross-sectional association between health and retirement is positive; i.e., those who retire later tend to be in better health. However, when the endogeneity of retirement is accounted for, the results change dramatically. Coe and Lindeboom (2008) find no negative effect from early retirement on male health; if anything, these authors report a temporary increase in self-reported health improvement in highly educated workers. Bound \& Waidmann (2008) find no evidence of negative health effects from retirement and some evidence that there may be a positive effect for males. Neumann (2007) finds, for subjective health measures, that retirement maintains health, but finds no effect on objective health variables. Charles (2002) focuses on mental health and finds that the direct effect of retirement on mental well being is positive. Our findings of strong ex ante mental health effects are consistent with the Charles (2002) findings.

Finally, the finding of ex ante effects of retirement on mental health has implications for the literature on the determinants of retirement decision making. The larger part of this vast literature focuses on the role of financial incentives on retirement behavior, with health included as an exogenous regressor (see e.g., the survey by Lumsdaine and Mitchell, 1999). For the identification of the causal effect of financial incentives on retirement it is generally believed that it is preferable to rely on exogenous changes in the retirement system. In the presence of ex ante health effects, changes in the retirement system will not only have an impact on the budget constraint, but will also influence health prior to retirement. This will confound both the health effects and the effect of financial incentives in retirement models. ${ }^{2}$

Our contribution is most closely related to the recent paper by Falba et al. (2008), which examines the impact on depression of deviation of actual retirement dates from their preceding expectations. The paper finds significant effects on depression at age 62 from those working more than expected and from those working less than expected. Our study differs from this paper in three important ways. First, we are able to exploit a natural experiment that generates a drastic change in the retirement system that is independent of health and that affects only a subgroup of workers. We link survey and

\footnotetext{
${ }^{2}$ Part of the effect of the financial incentives will be absorbed by the health effect if health changes prior to actual retirement. This suggests, moreover, that there are feedback effects of work on health, which in turn implies that health should be treated as an endogenous regressor in retirement models. See Bound and Waidmann (2008) for similar reasoning in the context of the effects of retirement on post-retirement health.
} 
administrative information of the pension fund. The survey was conducted in 2008 and consists of approximately 5,200 observations of fulltime working males born in 1949 and 1950. All individuals were informed about the policy change implemented in 2006. The limited age difference between the treatment and control groups in our sample and the simple and transparent age criterion determining entitlement to the old or new pension rights guarantees the internal validity of the experiment. Our findings are therefore less likely to be confounded. Second, our study shows that there are ex ante effects, that these are substantial and that they persist over time. Third, our data allow, to some extent, for further analysis of savings decisions and retirement expectations. This gives more insight into the mechanisms underlying our findings.

This paper proceeds as follows: Section 2 presents a brief description of the institutional setting in The Netherlands and the policy change that was implemented in January 2006. Section 3 describes the data and examines the validity of our natural experiment, i.e., whether individuals are aware of the reform and whether the treated group and the control group are comparable with respect to other characteristics. Section 4 presents the results of the empirical analyses. We analyze, in Section 5, whether the reform changes retirement savings and retirement expectations of the affected group. In Section 6, we further explore mechanisms that may explain our finding of higher depression rates among workers affected by the reform. We close with a discussion of our conclusions.

\section{$2 \quad$ The Dutch pension system}

The Dutch pension system consists of three pillars: 1) at age 65, all residents are entitled to a state old age pension financed by contributions that are levied along with the income tax; 2) most employees are entitled to an (early) supplementary sectoral or firm pension of the defined-benefit type; and 3) individuals can voluntarily build up savings typically taken as annuities through an insurance company. However, due to the supplementary pensions in the second pillar, the third pillar is less well developed in The Netherlands. For nearly all employees, early retirement before the age of 65 is possible only through 
the sectoral pension systems in the second pillar. In general for individual employees, participation in sectoral pension schemes is mandatory. These pension schemes are negotiated between unions and employer organizations at the sector or firm level and are officially set forth in collective agreements. The administration of these schemes is delegated to pension funds to which both employers and employees contribute. The 'Algemeen Burgelijk Pensioenfonds' (ABP) is the pension fund for public sector workers in The Netherlands. Until 2006, sectoral pension schemes were facilitated by the government through preferential tax treatment which granted large tax advantages due to the progressive tax system (Euwals et al., 2006). ${ }^{3}$

\section{Changes in the pension system for workers in the public sector}

The 2006 reform of the Dutch pension system provides the basis for our natural experiment. In line with its policy of stimulating the labor force participation of older workers, the government abolished the favorable tax treatment of early retirement schemes for all workers born after 1949. ${ }^{4}$ As in other sectors, anticipation of the change in tax rules formed an input to collective bargaining on the introduction of a new pension scheme for the public sector in the summer of 2005 ('ABP flexible pension scheme'). In light of demographic changes, it had by then been acknowledged that reform of the pension system would be a necessity. In that sense, a change in pension rights was not entirely unexpected. However, the timing of the reform as well as the particular implementation of a discontinuous assignment rule and the strong differential treatment of workers born around January 1, 1950 came as a surprise to public sector employees when it was announced on July 5, 2005.

The new pension scheme for public sector workers was launched on January 1, 2006. Workers born before 1950 remain entitled to the old, generous pre-pension rights if they have worked continuously in the public sector since April 1, 1997. This means that such workers can retire between age 55 and 65 . Retirement at age 62 years and 3 months yields a pension benefit at a replacement rate of $70 \%$ of average yearly earnings since

\footnotetext{
${ }^{3}$ Employees and employers were allowed to deduct their contribution to the sectoral early retirement schemes from their current income.

${ }^{4}$ The abolition of favorable tax treatment was not limited to the public sector but also applied to workers in the private sector.
} 
2002. However, employees born after 1949 and workers born before 1950 who did not work continuously in the public sector in the 10 years prior to retirement are subject to the new and less generous system. The new flexible pension system is characterized by: (i) a drop in pension benefits, (ii) an increase in pension contribution payments to partly account for the drop in pension wealth resulting from (i), and (iii) stronger incentives to continue working, generated by penalties on pension income when retiring before commencement of the state pension at age 65 and by supplements for later retirement. Moreover, the eligibility age for pension benefits is increased to 60 years and workers may decide to continue working until their 70th birthday. For younger workers, the increase in pension contributions partly compensates for the decrease in pension benefits over time. However, public sector workers born just after 1949 do not have enough time to compensate for this drop in pension benefits. Therefore, as a consequence of both the abolition of the tax rules and the steeper early retirement scheme, workers born after 31 December 1949 are confronted with a substantial decrease in pension benefits if they wish to retire at age 62 and 3 months. More specifically, the replacement rate drops to $64 \%$ and they must work an additional 13 months to qualify for a pension at a replacement rate of $70 \% .^{5}$

In 2006, the Dutch government also introduced the "Life course savings" program (Levensloopregeling). This program allows tax free saving of up to $12 \%$ of annual earnings in a fund that can be used to finance periods of non-employment, such as a sabbatical or early retirement. Workers are allowed to save up to a cumulative amount of $210 \%$ of their annual earnings in this "life course savings" fund, which can be used to finance about two years of early retirement. Note, however, that at a savings rate of $12 \%$, a worker needs to save for 17.5 years to reach the cumulative maximum of $210 \%$. Special arrangements were made for older workers who were most affected by the pension reform. Those who were born in the years 1950 through 1954 are allowed to save more than $12 \%$ of their annual earnings, so long as the cumulative maximum does not exceed $210 \%$ of annual earnings. It must be noted that workers of the 1950 cohort have to save

\footnotetext{
${ }^{5}$ Nevertheless, there is a small minority of older employees born after 1950 who can still retire early without experiencing a substantial drop in income. This pertains to employees with burdensome jobs (firemen, ambulance and police personnel) who are eligible for special arrangements that allow early retirement against a replacement rate of at least $70 \%$ between ages 55 and 61 . However, these workers are not included in our data.
} 
for seven years approximately $14 \%$ of their annual earnings to finance early retirement at age 62. It is likely that only a very small fraction of such workers are willing or capable of saving such a high proportion of their earnings each year before retirement.

The strong differential treatment of workers born around January 1, 1950 came as a surprise to public sector employees. However, for our empirical analyses it is important that workers born in 1950 are aware of the consequences of the new pension system for their individual situations. To make the introduction of the new pension system known to participants, ABP launched a campaign in the second half of 2005 to explain the implications of the new system. A special newspaper was devoted to the new pension system; in it, unions, employer organizations and ABP jointly explained the new flexible pension scheme. All 1.2 million ABP participants received a letter on the core characteristics of the new scheme and a complete electronic service pack for public service employers was developed. Therefore, we may assume that at 1 January 2006 most public sector employees born after 1949 and their employers were familiar with the exogenous shock in their pension rights. Of course this must be verified empirically. Since our data contain information on the replacement rate at age 62 , we can check whether those born after 1949 indeed predict their replacement rate to be lower than $70 \%$. We return to this issue at the end of the next section.

\section{$3 \quad$ Data}

\section{Matched survey and administrative data}

We use matched survey data and administrative data for male full time employees in the public sector who were born in 1949 or $1950 .{ }^{6}$ The administrative data come from the pension fund for public sector employees in The Netherlands (ABP). The data contain detailed information on annual wage income, the number of years of contribution and establishment size.

\footnotetext{
${ }^{6} \mathrm{We}$ focus on male employees because the male worker aged 57 or 58 is generally the main family wage earner. Moreover, in The Netherlands only a small group of women of this birth cohort is still working.
} 
The panel survey data are available for two years. The data in the initial wave were gathered in two stages, one year after the introduction of the new pension system. In the first stage, all 27,871 male public sector workers in the Netherlands who were born in 1949 or 1950 were sent a request to participate in the survey and to provide their e-mail address. ${ }^{7}$ In the second stage, those who gave permission $(11,458$ workers sent their email address) received an e-mail with a link to the survey. In total, 8,526 individuals answered the questionnaire, of which 7,739 completed it successfully. Analyses based on the administrative data show that the 7,739 respondents form a representative sample of the 27,871 male public sector workers in the Netherlands born in 1949 or 1950 .

In this study, we rely on data from the second wave of the survey, which was held in March 2008 and includes 6,078 employees of the public sector. ${ }^{8}$ In this wave, detailed questions were asked on mental and physical health, retirement expectations and job characteristics. The analysis is restricted to full time employees who have worked continuously in the public sector since $1997 .{ }^{9}$ For these workers, the pension reform is clear and simple, as age is the only criterion that determines whether a worker is eligible for the restricted or the more generous retirement scheme. The final sample consists of 5,195 men, of which 2,724 were born in 1950 (the treatment group) and 2,471 were born in 1949 (the control group).

Our primary interest lies in investigating how the change in the pension system affects the mental health of public sector workers. For measuring mental health, we use the CES-D8 indicator of depression, derived from the Center for Epidemiologic Studies Depression Scale (CES-D, Radloff 1977). The CES-D8 is a well validated instrument for measuring emotional function and depressive symptoms (see Blazer et al., 1991; Hays et al., 1993; Adams et al., 2003; Falba et al. 2008) and is used in many large samplepopulation based studies such as the US Health and Retirement Survey (HRS). The CESD8 consists of eight items, of which six are negatively phrased statements that reflect the presence of depressive symptoms (depression; that everything was an effort; restless

\footnotetext{
${ }^{7}$ This most likely does not affect the representativeness of the survey. At least $91 \%$ of the public workers aged 55 years or older have an internet connection at home (TNS-NIPO, 2006). Moreover, virtually all public sector workers have internet access at work.

${ }^{8}$ For the second wave, all individuals who started the questionnaire in 2007 received an e-mail with the link to the survey in March 2008.

${ }^{9}$ We therefore excluded 260 observations on employees born in 1949 who are not eligible for the old pension rights. This group is not large enough to serve as an additional control group.
} 
sleep; inability to get going; felt lonely; and felt sad). Two positively phrased statements reflect the absence of depressive symptoms (enjoying life and happiness). To create the variable used in our analyses, we first dichotomize (yes/no) responses and reverse the coding of the positively phrased items to achieve a count variable from 0 to 8 , where higher values suggest worsening depressive symptoms. In the next step, we construct a dummy variable that indicates whether workers are considered to be depressed. We used the suggested score of 4 and above, consistent with probable clinical depression (see Andresen et al., 1994; and Blazer et al., 1991).

In addition to mental health, we collected information about physical health, using both objective and subjective measures. First, we asked public sector workers the following question: In general, how would you describe your current health? Response categories ranged form 1 (very good) to 5 (bad). Second, we asked individuals to describe their health in comparison with other persons of the same age and in comparison with their health situation three years ago. Again, response categories ranged form 1 (very good) to 5 (bad). Thirdly, we asked how often individuals visited their doctor in 2007 and whether they were sick for more than 14 days. Lastly, we asked workers whether their health limits them in the kind and amount of work they are able to perform.

\section{Descriptives}

Table 1 presents descriptive statistics for the entire sample, the treatment group and the control group. The last column gives the results of a simple t-test for equality of the means of a variable for both groups. The table shows that on average $4.3 \%$ of all public sector workers are depressed as measured by our depression indicator. Workers with retrenched pension rights are relatively more depressed (5.0\%) than those who are not affected by the policy change (3.5\%). A simple t-test indicates that the difference between the two groups is significant at the $5 \%$ level $(\mathrm{t}$-stat $=2.63)$. A similar result is found for the raw CES-D8 score $(\mathrm{t}-\mathrm{stat}=2.03)$. This preliminary analysis indicates that there is a negative ex ante effect from the shock in the pension system on the mental health of workers nearing retirement. The table also shows that there are no significant differences in the averages of the physical health measures between the two groups. In 2007 , on average, workers visited their doctor twice, $17 \%$ of workers were sick more than 
14 days and 18\% indicated that their health limits them in their job. The t-statistics for the differences between the controls and the treated for number of doctor visits, self-reported health and the limitations question are $0.05,0.83$ and 0.28 , respectively.

For the validity of the natural experiment, it is important that the individuals in the treatment and control groups be sufficiently similar (apart from differential treatment in the pension system). Table 1 shows that most differences between the group of workers who are affected by the new pension system and the group that falls under the old system are indeed extremely small. Job characteristics, personal characteristics and wealth components are similar across both groups, and with a few exceptions, are not significantly different from each other. Concerning job characteristics, we observe that most public sector workers have mentally demanding work (67\%) and that they spend approximately $29 \%$ of their working time on non-routine tasks. ${ }^{10}$ Approximately $62 \%$ of public sector workers have a high education level and more than $91 \%$ are married. ${ }^{11}$ The fraction of married individuals is slightly higher among the group that is not affected by reform and this difference is significant at the $10 \%$ level. It will therefore be important to control for marital status in the multivariate analyses. We also see some very small yet significant differences between the two groups in work sector. The most recurrent wealth components are private savings (more than 15,000 Euros), net housing wealth and annuity insurance. Among the set of wealth variables, three variables are significantly different between the control and the treatment groups: the number of years individuals built up pension rights in the public sector pension fund; the response to a question on whether respondents undertook extra savings arrangements for their retirement in the past year; and the response to a question on whether individuals participated in the "Life course savings" program (see Section 2). The difference in the pension rights variable (tstat $=8.2)$ is due to the small age difference between the control and the treatment groups. The extra pension savings $(\mathrm{t}$-stat $=3.7)$ and participation in the "Life course savings" program $(\mathrm{t}$-stat $=9.3)$ are likely to be responses to the policy reform. In light of this, it is

\footnotetext{
${ }^{10}$ The questions on physically/mentally demanding work are based on two survey questions which asked how well they identified themselves with the following statements: I have physically (mentally) demanding work. Answer categories ranged form 1 (very good) to 5 (bad). For this table, the answer categories are dichotomized ( 1 corresponds to a score of 1 or 2 , and 0 corresponds to a score of 3 or higher).

${ }^{11}$ The public sector has an overrepresentation of highly educated workers. The fraction in our sample is consistent with the OSA labor supply panel, which is a representative panel survey of the working population in The Netherlands.
} 
noted that the government introduced favorable tax treatment for participation in the "Life course savings" program and in particular for those affected by the reform (see Section 2). Of the 1949 cohort, only 6\% participate in this "Life course savings" program. Of the 1950 cohort, this fraction is more than two times higher (about 15\%). In Section 5, we further explore individual savings behavior in response to the reform.

Respondents were asked three questions concerning their retirement expectations: 1) At what age did you expect to retire 5 years ago? 2) At what age do you expect to retire now? 3) Suppose, you would retire at the age of 62. How large would your pension benefit be as a percentage of your net wage income? The average response to the first question does not differ significantly between the treated and the control groups. However, we do find a significant difference between the two groups for the second question $(\mathrm{t}$-stat $=3.1)$, although this difference is relatively small. Those born in 1949 on average expect to retire at age 61 years and 8 months, while those born in 1950 expect to retire at age 62 years and 1 month. This small difference in expected retirement age could imply that many workers in the treatment group accept lower pension benefits because they do not want to change their retirement plans. Another possible explanation is that workers are not well enough informed about their pension rights or that they increased their private savings. In light of the latter variable, it is important to have a closer look at the response to the third question.

\section{Do people understand the consequences of the changes in the pension system?}

The averages in Table 1 show that respondents born in 1949 expect, on average, a pension income at the replacement rate of $72 \%$ at retirement age 62 , while employees born in 1950 anticipate a replacement rate of only $67 \%$ at this age $(\mathrm{t}$-stat $=16.0)$. These expectations are remarkably close to the actual replacement rates of $70 \%$ and $64 \%$, respectively, that they are forecast to receive based on past and projected pension contributions. Figure 1 shows expected replacement rates for workers born in 1949 and 1950. The dots represent expected average replacement rates for individuals born in a specific month. The first month corresponds to January 1949; the last month (number 24) corresponds to December 1950. The figure shows that there is a clear break in expectations around the threshold date (December 31, 1949). It seems reasonable to 
conclude from the figure that employees are indeed familiar with the consequences of the new pension system with respect to their individual situations.

\section{$4 \quad$ Results}

We operate simple linear probability models for whether an individual is depressed. The results are presented in Table 2. An individual is defined to be depressed if the CES-D8 score equals 4 or higher (see section 3 ). The table includes a base specification, where, apart from the indicator for the reform, no other variables are included. The remaining columns refer to specifications where, subsequently, additional controls are included. In specification II, we add a set of individual controls, including age, marital status, education, wage income, how many years the worker has contributed to the pension fund and job characteristics (sector of work). This specification excludes an indicator for whether individuals characterize their work as mentally or physically demanding, and the proportion of routine tasks. It is conceivable that depression status may have a direct effect on these variables. In specification III, we add a set of controls for personal wealth. Although our data set contains indicators for wealth aside from those included here, such as whether individuals have an annuity or a life insurance policy, whether they have more than 15,000 Euros in their bank account, and whether they participate in a life course savings program (see Table 1), we decide not to include these variables in the regressions because some of these variables may themselves be influenced by the reform and may therefore absorb some of the effect of the reform on depression.

For wealth variables that we do include, it is less likely that they are affected by the pension reform. However, there were some missing observations: the sample size is reduced to 3,314 observations if we omit those observations where at least one of the wealth variables is missing. We therefore include indicators for whether there was item non-response on each of the included wealth variables. ${ }^{12}$ In the last specification (IV) we include the three potentially endogenous job characteristics variables (whether the work

\footnotetext{
${ }^{12}$ We also run a regression where we include only these 3,314 observations. The coefficient of the reform was even higher (0.032 with standard error of 0.013$)$ and was significant at the 1 percent level.
} 
was mentally or physically demanding and the fraction of routine tasks) along with other health indicators and a health care utilization variable. One could argue that these health variables are potentially endogenous in the sense that they may relate to unobservable factors that also influence depression, or that causality may run from depression status to the health variable. Note however, that we find no differences between both groups for these health and job characteristics variables (see Table 1 and the discussion in the data section). Inclusion of these variables controls for individual heterogeneity and it is therefore expected that such inclusion will have little impact on the estimate of the reform indicator. A comparison of the reform dummy in specifications III and IV will be informative on this issue.

The results displayed in the table are very clear: in all specifications the reform has significant effects on mental health and the magnitude of these effects increases when we add controls for individual heterogeneity. These effects are sizeable. For instance, the coefficient in the last specification (specification IV) is 0.028 , which implies an additional effect of 2.8 percentage points on top of the average depression rate (on the order of $3.5 \%-5.0 \%$ ). The other variables in Table 2 show the expected signs. For example those who are married have a lower probability of being depressed; the same holds for those whose partner has a pension or an income. The health variables are all strongly significant, although these effects may be biased as discussed above. We see however, no large changes in the reform indicator across the different specifications in columns II, III and IV. Next, we perform analyses on the total CES-D8 score. This variable ranges from 0 to 7 and shows substantive heaping at the 0 score. Following Falba et al. (2008), we estimate a Poisson model; ${ }^{13}$ the results are reported in Table A1 of the appendix and they indicate that the reform has a significant impact on CES-D8 score.

We also perform regressions on subsamples for different age windows around the treatment threshold. We include these regressions for two reasons. First, it is conceivable that effects from the reform may be particularly strong for individuals who barely missed the old generous pension system by a few days, weeks or months. After all, the deadline of December 31, 1949 is arbitrary and given that there is an effect from the pension reform on the depression rate, one may expect that this effect will be stronger on those

\footnotetext{
${ }^{13}$ A regression of $\log (\mathrm{CES}-\mathrm{D} 8+1)$ gave similar results.
} 
who, by fate, just missed the threshold. A second reason is that we include age in the specifications of Table 2 as the number of days after January 1, 1949. Clearly age should be controlled for as this may be a relevant factor for depression. At the same time, there is little variation in the age variable and it clearly correlates with the reform dummy; this may affect our results. By omitting the age variable in the regressions, but nevertheless estimating the regressions for different age windows, we address the issue of the sensitivity of our findings to the inclusion of the linear age variable.

The results are presented in Table 3. The table reports only the coefficients of the reform indicator, but all regressions include the full set of controls, as in specification IV of Table 2. Table 3 shows that the effect of the reform is stronger for those born near the threshold date and that the effect gradually decreases with a wider window around the threshold date. We think that the age range for the smallest window is too small for age effects to be relevant. Therefore, the coefficient of 0.024 for the treatment effect can be expected to be a reliable estimate of the causal impact of the reform. This coefficient is only slightly smaller than the 0.028 that we obtained from specification IV in Table 2, where age is included as a linear trend. This adds confidence to the estimates presented in Table 2.

The pattern in the coefficients of Table 3 suggests that those who were born just after the threshold date (January - March 1950) are more depressed than those who were born later in the year (April - December 1950). The average depression rate for those born in the January - March 1950 period is 0.053 , compared to 0.048 for their younger counterparts born in the April - December 1950 period. However, a simple t-test shows that this difference is not significant $(\mathrm{t}$-stat $=1.0)$. Alternatively, there could be a "relief effect," meaning that particularly those who just qualified (i.e., those born October December 1949) have lower depression rates. We therefore check the depression rates for several groups. The average depression rate for those born October - December 1949 is 0.027 , whereas the depression rate for their older counterparts (January - September 1949) who also qualified for the old generous pension system is 0.036 . This suggests a relief effect. A t-test, however, revealed that the differences between these two groups is also not significant $(t-s t a t=0.5)$. However, the insignificance of these effects could be 
due to the relatively small number of observations around the threshold date (approximately 550 observations for each group on either side of the threshold date).

Further, we analyze whether the pension reform differentially affects different types of workers. Table 4 presents the results of separate analyses on subsamples. The regressions include the same set of explanatory variables as in specification IV of Table 2, but again we here report only the coefficient for the reform indicator. The table shows that there can be substantial differences in the impacts of the reform for different subgroups. The effects are in the expected direction. For instance, those who are not married experience a substantially greater effect from the reform, although the effect is significant only at the $10 \%$ level, which may be due to the low number of unmarried males in our sample. The reform has the greatest financial consequences for those with a higher income and those with nearly full pension rights (measured by number of years contributing to the pension fund). Indeed, the effect of the reform on mental health is also highest for these workers. Similarly, workers whose partners have a pension or an income are likely to be less affected by the income shock due to the pension reform. We also note that for this group the reform has no significant impact on the depression rate. ${ }^{14}$

The estimation results presented in Tables 2, 3 and 4 are all consistent with strong ex ante effects from the pension reform on mental health. Is it likely that our findings are due to some artifact? Could it be that the reform caused some workers who are less prone to depression to leave the public sector and that this effect is stronger for the 1950 cohort? This effect is not likely. Public sector pensions are relatively generous and, along with the pension reform in the public sector, all other sectors changed their pension plans because the preferential tax treatment of pension premiums was abolished for both public and private sector workers. Further, job mobility rates out of the public sector into the private sector are extremely low for older workers. When moving to another sector, it is likely that these workers will not only incur costs associated with a change in pension fund, but that they will entirely loose their rights to retire before age 65 . The majority of

\footnotetext{
${ }^{14}$ It would have been interesting to see whether the partner is also affected by the reform and examine whether the treatment effect differs with respect to this. However, we only know the age of the partner and whether the partner has an income. The latter variable is already included in the analyses. We therefore did not pursue this issue further.
} 
pensions in The Netherlands impose not only an age criterion but also a minimum number of tenure years within a sector or sometimes even a firm (Euwals et al., 2006).

We drop individuals who worked continuously in the public sector only since 1997. It is conceivable that those with mental health problems are more likely to have gaps in their employment history and therefore do not pass this selection criterion. However, this could affect our results only if this affects the treated cohort (that of 1950) differently than the 1949 cohort. There is no reason to expect this. Moreover, when this is the case, one would expect to see this reflected in other factors that are correlated with depression (such as marital status) or with gaps in employment (income for instance). As discussed in Section 3, we see no differences in the observed variables between the two groups (see Table 1). We run additional regressions in which we add this group to the sample (216 full-time workers) and include a dummy variable for this group in addition to whether workers of this group were born in 1950. Both coefficients are insignificant, indicating that the mental health status of this group does not differ from workers born in 1949 and those who worked continuously since 1997 (the controls).

Are there other factors that differ between the two groups, such as the level of education? The averages in Table 1 reveal no important differences in this respect. Furthermore, we are aware of no changes in the system that may have differentially affected the 1950 (1949) cohort as opposed to the 1949 (1950) cohort.

\section{Behavioral responses}

One important question is whether the reform has affected the savings behavior and/or the retirement behavior of those affected, as workers with retrenched pension rights may save more in order to maintain their previously planned retirement date. In a recent paper, Delavande and Rohwedder (2008) explore this issue with respect to the US. They used an internet survey in which they asked the respondents of the Health and Retirement Survey (HRS) what they would do if their Social Security benefits were cut by 30 percent. The authors found that on average individuals would then postpone retirement by 1.13 years. About two-thirds indicated that they would reduce their spending to compensate for the 
drop in pension wealth. Our survey includes two savings questions and one question on expected retirement age that enable us to analyze such behavioral responses.

\section{Savings behavior}

The first savings question asks whether the respondent undertook additional savings arrangements for their pension in the past year. The second question addresses whether the respondent participates in the "Life course savings" program (see Section 2). In Table 5 , we report the results from analyses of the savings question. Columns 1 and 2 report results from the first question, columns 3 and 4 report results from the second question. The first two columns of Table 5 show a strong effect from the reform on additional pension savings if no controls are included. The coefficient is positive, indicating that those who are affected by the reform engaged in additional savings in the past year to compensate for the loss in pension wealth. However, the effect becomes insignificant when we include the full set of regressors. Columns 3 and 4 show strong effects from the pension reform on participation in the "Life course savings" program. The results of column 3 reflect what we see in Table 1: the reference group (1949) has a participation rate of around 6 percent, whereas the participation rate of the affected cohort is about nine percentage points higher. Adding controls reduces the magnitude of the reform effect, but the effect is nevertheless substantial and strongly significant. Unfortunately, we cannot observe how much participants save yearly in the "Life course savings" program. Workers in the 1950 cohort would have to save for seven years about $14 \%$ of their annual yearly earnings to finance early retirement at the age of 62. It is likely that only a small fraction of participants is able and willing to save such a high share of their earnings each year prior to retirement.

\section{Expected retirement age}

Figures $2 \mathrm{a}$ and $2 \mathrm{~b}$ give a histogram of expected retirement ages (At what age do you expect to retire now?), and figures $3 \mathrm{a}$ and $3 \mathrm{~b}$ of expectations 5 years ago (At what age did you expect to retire 5 years ago?). From Figures $3 \mathrm{a}$ and $3 \mathrm{~b}$, one may conclude that the distribution of expected retirement ages five years ago was virtually identical for the 1949 and 1950 cohorts. However, this is very different for Figures 2a (affected by the reform) 
and $2 \mathrm{~b}$ (not affected by the reform). Compared to the 1949 cohort, a much larger share of those treated expects to retire at age 65 . On the other hand, quite surprisingly, rather equal fractions of both the treated and the control groups expect to retire at age 57 or 58 . The treated workers may harbor no such expectation, because in the new system they cannot receive pension benefits prior to age 60 (see Section 2). It could be that these workers do not fully understand all details of the new system. However, Figure 1 shows clearly that the cohort that is affected by the reform understands the implications for their replacement rate if they wish to retire at age 62. Alternatively, it could be that these are workers who decide to stop working in the public sector or that they are more likely to leave the labor force via alternative exit routes like disability insurance. The data allow us to check the latter proposition to some extent. We examine prevalence rates for other health variables (self-assessed health, the response to the limitations question, the number of visits to the doctor and whether respondents were sick more than 14 days in the past year) for this group and the other respondents born in 1950 and find no difference with respect to these health variables. Also, the depression rates for this group are similar to the rates of others born in 1950.

In Table 6, we report the results of further analysis on the expected retirement age. The table shows that the reform has a significant effect on the expected age of retirement, but this effect is significant only at the $10 \%$ level when the full set of controls is added to the specification. The coefficient of 0.274 amounts to about 4 months' postponement of retirement. This is lower than the effect found by Delavande and Rohwedder (2008), but in their hypothetical situation they asked respondents to indicate what they would do when the Social Security benefit is reduced by $30 \%$. Furthermore, those affected by the reform are more likely to participate in the "Life course savings" program (see Table 5), which may partially compensate for the loss in pension wealth. We also perform a regression on the probability of late retirement (later than age 63). This regression indicates that the probability of late retirement is increased by 16 percentage points and that this effect is significant at the $1 \%$ level. 


\section{$6 \quad$ Why is the affected cohort so depressed?}

An important question is why the reform has such a strong impact on mental health? One possibility is that (the prospect of) longer working in itself causes decreased mental health. We explore this by examining the effect of expectations about the retirement age on depression. For this, we use an Instrumental Variable (IV) approach in which we instrument expected retirement age with the reform dummy. ${ }^{15}$ The coefficient of the expected retirement age is equal to 0.1005 and is not significant at the standard levels (s.e. $=0.077)$. However, the F-test of the first-stage regression suggests a weak instruments problem (the F-statistic equals 4.52, which is well below the value of 10 suggested by Staiger \& Stock, 1997). We also examine the effect of expected late retirement (later than age 63) on mental health. The IV regression reveals a positive and strongly significant coefficient $(0.162$, s.e. 0.0078). The F-test of this first stage regression equals 18.61 (tables not reported, but available upon request). This finding is in line with Charles (2005), who finds that later retirement has adverse effects on mental health.

Finding a negative effect from late expected retirement on mental health, however, does not rule out that other mechanisms may be at work that cause the relatively high depression rate of the 1950 cohort. We therefore regress the depression indicator on the savings and expected retirement age variables. The regressions also include a full set of other controls. The idea is that if, for instance, late expected retirement is the prime factor driving the higher depression rates among the 1950 cohort, then one would expect to see a large effect from this variable and little or no effects from the reform indicator (treatment dummy). The results of these analyses (reported in Table 7) show that the reform indicator remains large and strongly significant after inclusion of savings variables and expectations variables. One can conclude from this that apparently factors other than (forced) savings and later retirement are responsible for the relatively high depression rate among those affected by the reform.

Another potential factor is the way in which the pension system reform was set up. The 2006 reform of the pension system represented a major change that added to previous

\footnotetext{
${ }^{15}$ It is likely that retirement age expectations are endogenously related to the depression rate. Either because there are feedback effects from depression on retirement expectations, or because there are unobservables that correlate both to depression and individual expectations.
} 
reforms in the retirement system. In particular, the 1949 cohort was the last cohort that was allowed to retire at relatively young ages against relatively generous replacement rates. The 1950 cohort is the first cohort that must work longer against substantially lower replacement rates. Further, this group of workers faces this new situation with relatively short notice - too short to completely offset the change in the system with additional savings. The change in the pension system was not entirely unexpected, but the particular type of discontinuous assignment rule and the strong differential treatment of workers born around January 1, 1950 came as a surprise when announced in July 2005. Anecdotal evidence suggests that it was perceived to be unfair. For more on this issue, see Montizaan et al. (2009), who use the same data as this paper to examine the relation between job motivation and reciprocity. ${ }^{16}$ Their main finding is that job motivation declines among negatively reciprocal individuals who face an unexpected drop in pension rights, while no effect is found among non-reciprocal employees. We therefore also estimate separate models for negatively reciprocal individuals and non-negatively reciprocal individuals. The measure of negative reciprocity is derived from the responses to three questions. ${ }^{17} \mathrm{~A}$ worker is defined to be negatively reciprocal if his score falls above the median score. We find that negatively reciprocal individuals have a much stronger response to the reform than non-negatively reciprocal workers. The coefficients are 0.044 (s.e. of 0.017 ) and 0.013 (s.e. of 0.014) for negatively reciprocal and non-negatively reciprocal individuals, respectively. This suggests that indeed feelings of unfair treatment may drive much of the strong effects from the reform on mental health.

Our findings also relate to the literature on individual well being and happiness. This literature finds that individual well being may be affected by income, but also by the difference between one's own income and the income of a reference group (see for an overview, Clark et al., 2008). Ferrer-i-Carbonell (2005) finds that the income of the reference group is about as important as own income for individual happiness. Calvo, Haverstick and Sass (2007) examine the factors that affect individual happiness in the transition to retirement. Their results suggest that what really matters is whether people

\footnotetext{
${ }^{16}$ Negative reciprocity is an in-kind response to hostile acts which indicates retaliatory tendencies.

${ }^{17}$ Respondents had to respond to how much (ranging form $1=$ not at all to $5=$ fits me completely) they identified themselves with each of the following statements: 1) If I suffer a serious wrong, I will take up revenge no matter what the costs; 2) If somebody puts me in a difficult position, I will do the same to him or her; 3) If somebody insults me, I will give an insult back.
} 
perceive the transition from work to retirement as chosen or forced. These authors suggest that it is the sense of control over their own retirements that influences the happiness of older workers. It appears clear that control over one's own retirement is a problem for Dutch workers born in 1950. For cohorts born in later years, this is presumably less of a problem as the longer period before retirement allows them to better compensate for their loss of pension wealth. Unfortunately we cannot test this with our data.

\section{$7 \quad$ Discussion and conclusions}

The reform that affected the pension wealth of the younger (1950) cohort had a strong impact on their mental health. Our analysis reveals that those who by chance are exposed to a pension reform that confronts them with substantially lower pension wealth have higher depression rates. This effect persists over time and grows stronger the closer one is born to the threshold date. Furthermore, we find differing effects for different types of workers. For instance, the effects are stronger for unmarried workers and negligible for workers whose partner has a pension or an income. Finally, we find that those affected by the reform also respond by working an additional four months and that they are more likely to participate in a savings program that is likely to only partially compensate for the loss in pension wealth. Our data do not allow us to give a definitive answer to the questions of why the depression rate of the affected group is so much higher and why this effect persists over time. We find that later expected retirement is important for mental health, but other factors are also at work. The discontinuous assignment rule and the strong differential treatment of workers born around January 1, 1950 is perceived to be unfair, especially because it was announced only a few years before the retirement date of the affected workers. Too little time remained to allow these workers to fully offset the loss in pension wealth. Workers were suddenly forced into a new situation with little control over their retirement decision; this may have affected their mental health.

Our findings have great relevance for public policy. Currently, most countries in the developed world are revising their pension systems to cope with population aging. The reforms are geared toward extending working life and to a smaller role for defined 
benefit pensions. Furthermore, a substantial part of the pension wealth of workers has recently evaporated due to the current financial crises. Changes in worker pension claims, due either to financial crises or to government pension policy changes, will have severe consequences for most workers nearing retirement. Workers either must accept a substantial drop in pension wealth, increase pension contributions and/or work substantially longer than they expected before the current crisis. The results of this study show that this sudden irreversible deterioration of future prospects can have serious consequences for the mental health of workers nearing retirement, especially when the period before the planned retirement is too short to compensate for losses in pension wealth. In the longer run these mental health effects may translate into somatic diseases. This will not only affect individual well being, but it will also engender costs associated with depression and worse physical health, such as direct health care costs and indirect costs due to loss of productivity, flawed decision making, and workplace accidents. Governments should take these effects and costs into account when redesigning pension policies. 


\section{References}

Adams, Owen, and Louis. Lefebvre (1981). "Retirement and Mortality." Aging and Work; 4:115-120.

Adams, Peter Hurd, Michael D., McFadden, Daniel, Merrill, Angela and Tiago Ribeiro (2003). "Healthy, wealthy, and wise? Tests for direct causal paths between health and socioeconomic status" Journal of Econometrics, 112(1): 3-56.

Andresen Elena M., Malmgren Judith A., Carter William B. and Donald L. Patrick (1994). Screening for depression in well older adults: evaluation of a short form of the CES-D (Center for Epidemiologic Studies Depression Scale). American Journal of Preventive Medicine, 10(2):77-84.

Blazer, Dan, Burchett, Bruce, Service, Connie and Linda K. George (1991). "The association of age and depression among the elderly: an epidemiologic exploration," Journal of Gerontology: 46(6): M210-15.

Bound, John and Timothy Waidmann (2008). Estimating the Health Effects of Retirement, Working paper University of Michigan, July 2008.

Bradford, Leland P. (1979). “Can You Survive Your Retirement?" Harvard Business Review 57(4): 103-109.

Burgard, Sarah A., Bran, Jennie E., and James S. House (2007). "Toward a better understanding of the effect of job loss on health," Journal of Health and Social Behavior, 48(4): 369-384.

Calvo, Esteban., Haverstick, Kelly and Steven Sass (2007). What makes retirees happier: A gradual or 'Cold Turkey' retirement?, Center for Retirement Research Working paper.

Casscells, Ward, Evans, Denis, DeSilva, Regis A., Davies, John E., Hennekens, Charles H., Rosner, Bernard, Lown, Bernard and Mary J. Jesse. (1980). "Retirement and Coronary Mortality," Lancet; I(8181): 1288-1289.

Charles, Kerwin (2004). Is retirement depressing?: "Labor Force Inactivity and Psychological Well-being in Later Life," Research in Labor Economics; 23, eds. S.W. Polacheck.

Clark, Andrew, Frijters, Paul and Micheal A. Shields (2008). "Relative Income, Happiness and Utility: An Explanation for the Easterlin Paradox and Other Puzzles" Journal of Economic Literature; 46(1): 95-144.

Coe, Norma and Maarten Lindeboom (2008). Does retirement kill you? Evidence from early retirement windows, IZA working paper no. 3817, Netspar working paper. 
Delavande, Adeline and Susann Rohwedder (2008). Individual responses to social security reform, Michigan retirement research Center working paper, WP2008-12.

Dhaval, Dave, Rashad, Inas and Jasmina Spasojevic (2006). The effects of Retirement on Physical and mental Health Outcomes, NBER WP12123.

Ekerdt, David J., Baden, Lynn, Bosse, Raymond and Elaine Dibbs (1983a). "The Effect of Retirement on Physical Health," American Journal of Public Health; 73(7): 779-783.

Ekerdt, David J., Bosse, Raymond, and Joseph S. LoCastro (1983b). "Claims that Retirement Improves Health," Journal of Gerontology; 38.

Euwals, Rob, Van Vuuren Daniel J. and Ronald P. Wolthoff (2006) "Early Retirement Behaviour in the Netherlands: Evidence from a Policy Reform," IZA working paper no. 1992, CPB working paper no. 52.

Falba, Tracy., Gallo, William. and Jody. Sindelar (2008). Work expectations, realizations and depression in older workers, NBER working paper 14435, October 2008.

Ferrer-i-Carbonell (2005). "Income and Well-being: an empirical analysis of the comparison income effect," Journal of Public Economics; 89(5-6): 997-1019.

Gonzales, Edgar.R. (1980). "Retiring May Predispose to Fatal Heart Attack," Journal of the American Medical Association; 243:13-14.

Hays, Judith C., Blazer Dan G., and Deborah T. Gold (1993). "CES-D: cutpoint or change score?" Journal of the American Geriatrics Society; 41(3); 344-345.

Haynes, Simon G., McMichael, Anthony J. and Herman A. Tyroler. (1978). "Survival After Early and Normal Retirement," Journal of Gerontology; 33: 269-278.

Kapteyn Arie and Klaas de Vos (1998). "Social Security and Retirement in the Netherlands." In Social Security and Retirement around the World, Gruber Jonathan, and David A. Wise (eds). NBER: Chicago.

Kasl, Stanislav V. (1980). "The Impact of Retirement." In Current Concerns in Occupational Stress, C.L. Cooper and R. Payne (eds). New York: John Wiley.

Lindeboom, Maarten, Portrait, France and Gerard J. Van den Berg (2002) "An Econometric Analysis of the Mental-Health Effects of Major Events in the Life of Older Individuals." Health Economics. 
Lumsdaine Robin L. and Olivia S. Mitchell (2000). New developments in the Economic Analysis of Retirement. In Handbook of Labor Economics, Ashenfelter Orley and David Card (eds). Elsevier: North-Holland. Vol 3, Ch 49, 3261-3307.

Minkler, Merideth (1981). "Research on the Health Effects of Retirement: An Uncertain Legacy,” Journal of Health and Social Behavior; 22(2), (June): 117-130.

Montizaan Raymond, Cörvers, Frank, De Grip, Andries and Thomas Dohmen, (2009). Demotivating Workers: Retrenchment of pension rights and negative reciprocity, Working paper.

Neuman, Kevin (2007). "Quit Your Job and Get Healthier? The Effect of Retirement on Health” Journal of Labor Research; 29(2): 177-201.

Niemi, Tapio (1980) "Retirement and Mortality." Scandinavian Journal of Social Medicine; 8: 39-41.

OECD (2008) “Employment Outlook,” 2008(4): 203 - 262, Paris.

Radloff Leonore S. (1977). "The CES-D Scale: A self-report depression scale for research in the general population," Applied Psychological Measurement; 1:385-401.

Staiger, Douglas. and James H. Stock (1997), "Instrumental Variables Regression with Weak Instruments," Econometrica 65(3): 557-586.

Tsai, Shan P, Wendt, Judy K., Donnelly, Robin P., de Jong, Geert and Farah S. Ahmed. (2005). "Age at Retirement and Long Term Survival of an Industrial Population: Prospective Cohort Study,” British Medical Journal, doi:10.1136/bmj.38586.448704.EO. Oct 21.

TNS Nipo, 2006. ABP marktmonitor 12-meting e5351, Amsterdam.

WHO (2006). "The world health report 2006: working together for health" Geneva. 


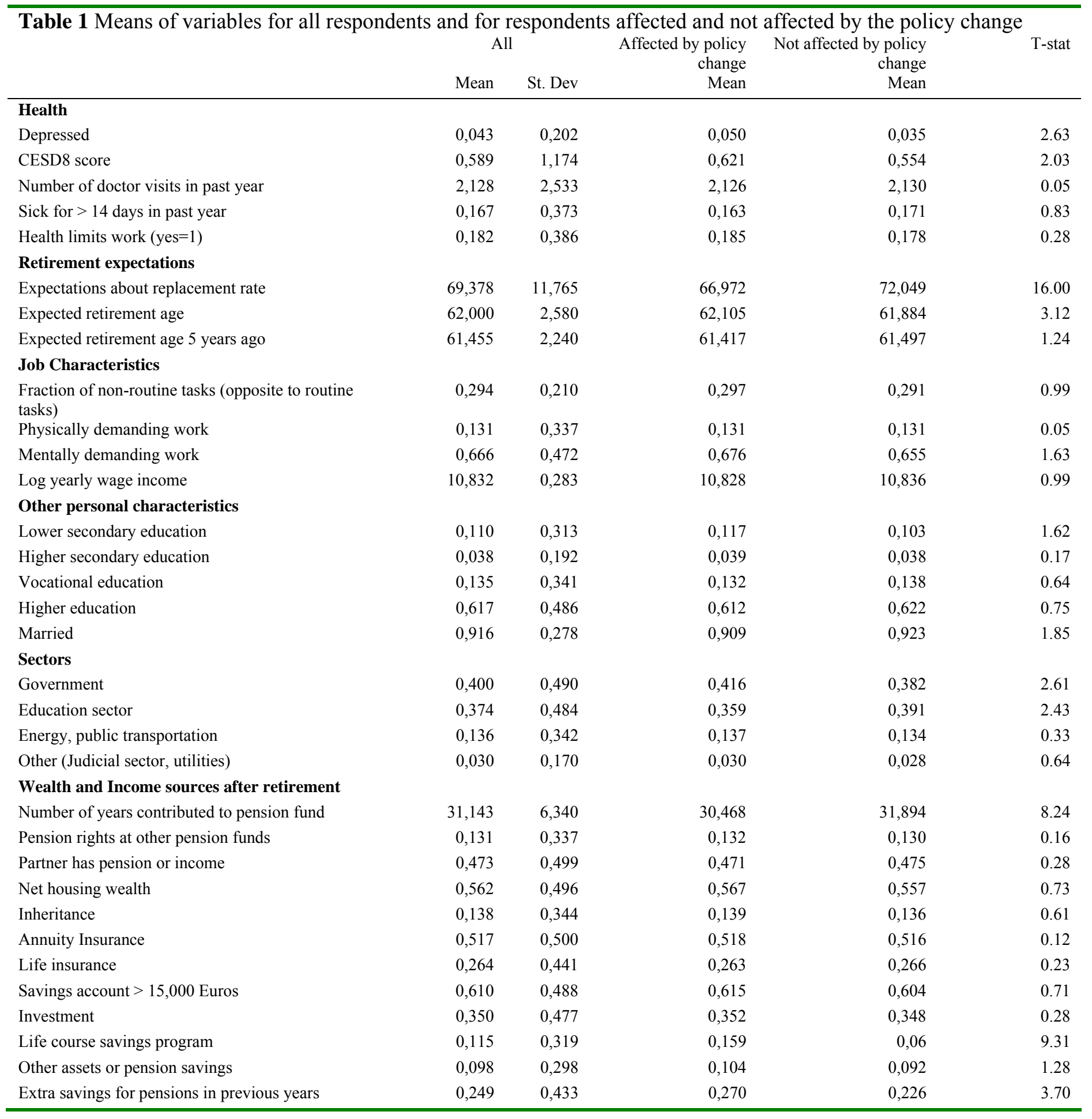




\begin{tabular}{|c|c|c|c|c|}
\hline Table 2 The effect of the policy chang & mental $\mathrm{h}$ & lth (Depr & on indica & $\mathrm{EESD} 8 \geq 4$ \\
\hline VARIABLES & I & II & III & IV \\
\hline Treated (affected by the policy) & $0.015^{* * *}$ & $0.026^{* *}$ & $0.026^{* *}$ & $0.028^{* *}$ \\
\hline & $(0.006)$ & $(0.012)$ & $(0.012)$ & $(0.011)$ \\
\hline Age (in days divided by 100 ) & & 0.003 & 0.003 & 0.003 \\
\hline & & $(0.003)$ & $(0.003)$ & $(0.003)$ \\
\hline Married & & $-0.044 * * *$ & $-0.037 * * *$ & $-0.035^{* * *}$ \\
\hline & & $(0.011)$ & $(0.011)$ & $(0.011)$ \\
\hline Lower secondary education & & 0.003 & 0.005 & 0.001 \\
\hline & & $(0.011)$ & $(0.011)$ & $(0.011)$ \\
\hline Higher secondary education & & -0.009 & -0.003 & -0.008 \\
\hline & & $(0.016)$ & $(0.016)$ & $(0.016)$ \\
\hline Higher education & & 0.005 & 0.011 & 0.008 \\
\hline & & $(0.009)$ & $(0.010)$ & $(0.009)$ \\
\hline Government & & -0.002 & -0.002 & -0.012 \\
\hline & & $(0.017)$ & $(0.017)$ & $(0.016)$ \\
\hline Education sector & & 0.002 & 0.003 & -0.017 \\
\hline & & $(0.017)$ & $(0.017)$ & $(0.017)$ \\
\hline Energy, public transportation & & -0.006 & -0.009 & -0.025 \\
\hline & & $(0.018)$ & $(0.018)$ & $(0.018)$ \\
\hline Physically demanding work & & & & -0.002 \\
\hline & & & & $(0.009)$ \\
\hline Mentally demanding work & & & & $0.024 * * *$ \\
\hline & & & & $(0.006)$ \\
\hline Fraction of non-routine tasks & & & & $-0.026^{*}$ \\
\hline & & & & $(0.014)$ \\
\hline Log yearly wage income (divided by 100 ) & & $-3.743 * * *$ & $-3.712 * * *$ & -1.484 \\
\hline & & $(1.264)$ & $(1.270)$ & $(1.264)$ \\
\hline$\#$ of years contributed to the pension fund $(/ 100)$ & & 0.073 & $0.094 *$ & $0.094^{* *}$ \\
\hline & & $(0.046)$ & $(0.049)$ & $(0.047)$ \\
\hline Pension rights at other pension funds & & & $0.016^{*}$ & 0.011 \\
\hline & & & $(0.010)$ & $(0.009)$ \\
\hline Partner has pension or income & & & $-0.022 * * *$ & $-0.018 * * *$ \\
\hline & & & $(0.007)$ & $(0.007)$ \\
\hline Net housing wealth & & & 0.003 & 0.009 \\
\hline & & & $(0.007)$ & $(0.007)$ \\
\hline Inheritance & & & $-0.016^{*}$ & -0.012 \\
\hline & & & $(0.009)$ & $(0.008)$ \\
\hline Missing info on other pension & & & 0.010 & 0.002 \\
\hline & & & $(0.014)$ & $(0.013)$ \\
\hline Partner info missing & & & -0.024 & -0.015 \\
\hline & & & $(0.015)$ & $(0.014)$ \\
\hline Net housing wealth missing & & & 0.017 & 0.020 \\
\hline & & & $(0.014)$ & $(0.014)$ \\
\hline Info on inheritance missing & & & -0.002 & -0.002 \\
\hline & & & $(0.012)$ & $(0.011)$ \\
\hline Self-reported general health & & & & $0.034 * * *$ \\
\hline & & & & $(0.005)$ \\
\hline Self-reported work limitations & & & & $0.066^{* * *}$ \\
\hline & & & & $(0.009)$ \\
\hline Number of doctor visits in past year & & & & $0.007 * * *$ \\
\hline & & & & $(0.001)$ \\
\hline Sick for $>14$ days in past year & & & & $0.028 * * *$ \\
\hline & & & & $(0.009)$ \\
\hline Observations & 5,195 & 4,854 & 4,854 & 4,765 \\
\hline R-squared & 0.001 & 0.009 & 0.012 & 0.101 \\
\hline$* * * p<0.01, * * p<0.05, * p<0.1$. Standard err & arenthese & & & \\
\hline
\end{tabular}




\begin{tabular}{|c|c|c|c|c|}
\hline VARIABLES & $\begin{array}{c}\text { Born within } 3 \\
\text { months of } 1-1-1950\end{array}$ & $\begin{array}{c}\text { Born within } 6 \\
\text { months of 1-1-1950 }\end{array}$ & $\begin{array}{c}\text { Born within } 10 \\
\text { months of } 1-1-1950\end{array}$ & $\begin{array}{l}\text { Born within } 12 \\
\text { months of } 1-1-1950\end{array}$ \\
\hline Treated (affected by the policy) & $\begin{array}{c}0.024 * * \\
(0.011)\end{array}$ & $\begin{array}{c}0.022 * * * \\
(0.008)\end{array}$ & $\begin{array}{c}0.020^{* * *} \\
(0.006)\end{array}$ & $\begin{array}{c}0.016^{* * *} \\
(0.006)\end{array}$ \\
\hline Observations & 1,168 & 2,407 & 3,557 & 4,765 \\
\hline R-squared & 0.126 & 0.116 & 0.100 & 0.101 \\
\hline Standard errors in parentheses ** & $p<0.05, * p<0.1$ & & & \\
\hline
\end{tabular}

The regressions include the same set of regressors as in specification IV of Table 2 (a set of health variables, individual and job characteristics and selected wealth variables).

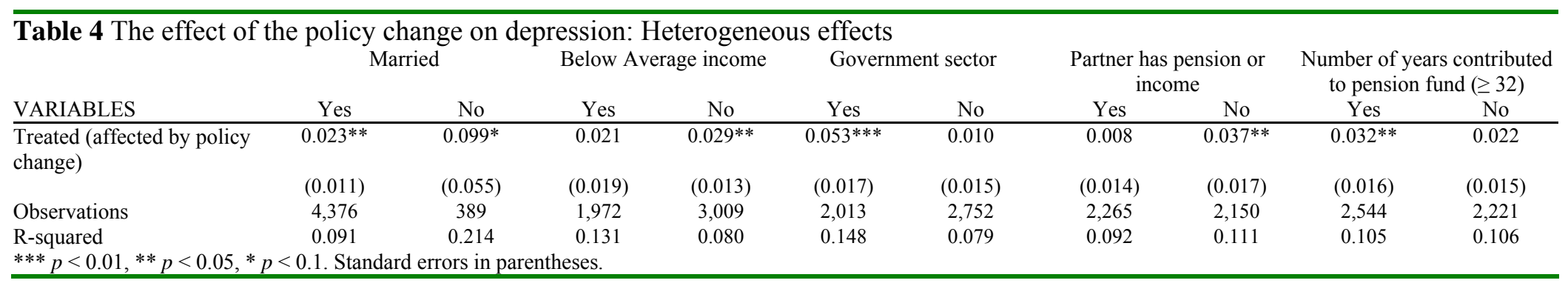

The regressions include the same set of regressors as in specification IV of Table 2 (a set of health variables, individual and job characteristics and selected wealth variables). 


\begin{tabular}{|c|c|c|c|c|}
\hline \multirow[b]{2}{*}{ VARIABLES } & \multicolumn{2}{|c|}{ Extra pension savings } & \multicolumn{2}{|c|}{ Life course savings } \\
\hline & I & II & III & IV \\
\hline Treated (affected by the policy) & $\begin{array}{c}0.044 * * * \\
(0.012)\end{array}$ & $\begin{array}{c}0.011 \\
(0.024)\end{array}$ & $\begin{array}{c}0.091 * * * \\
(0.008)\end{array}$ & $\begin{array}{c}0.052 * * * \\
(0.019)\end{array}$ \\
\hline Age (in days divided by 100 ) & & $\begin{array}{l}-0.006 \\
(0.006)\end{array}$ & & $\begin{array}{l}-0.005 \\
(0.005)\end{array}$ \\
\hline Married & & $\begin{array}{c}0.027 \\
(0.023)\end{array}$ & & $\begin{array}{l}-0.008 \\
(0.018)\end{array}$ \\
\hline Lower secondary education & & $\begin{array}{l}-0.031 \\
(0.024)\end{array}$ & & $\begin{array}{c}-0.012 \\
(0.020)\end{array}$ \\
\hline Higher secondary education & & $\begin{array}{c}0.025 \\
(0.034)\end{array}$ & & $\begin{array}{l}-0.020 \\
(0.027)\end{array}$ \\
\hline Higher education & & $\begin{array}{l}0.035^{*} \\
(0.021)\end{array}$ & & $\begin{array}{c}0.008 \\
(0.017)\end{array}$ \\
\hline Government & & $\begin{array}{l}-0.015 \\
(0.036)\end{array}$ & & $\begin{array}{c}-0.019 \\
(0.029)\end{array}$ \\
\hline Education sector & & $\begin{array}{c}0.014 \\
(0.037)\end{array}$ & & $\begin{array}{l}-0.011 \\
(0.029)\end{array}$ \\
\hline Energy, public transportation & & $\begin{array}{l}-0.013 \\
(0.039)\end{array}$ & & $\begin{array}{c}0.028 \\
(0.033)\end{array}$ \\
\hline Physically demanding work & & $\begin{array}{l}0.034^{*} \\
(0.021)\end{array}$ & & $\begin{array}{c}0.016 \\
(0.017)\end{array}$ \\
\hline Mentally demanding work & & $\begin{array}{l}0.026^{*} \\
(0.014)\end{array}$ & & $\begin{array}{c}0.006 \\
(0.011)\end{array}$ \\
\hline Fraction of non-routine tasks & & $\begin{array}{c}0.020 \\
(0.030)\end{array}$ & & $\begin{array}{c}0.014 \\
(0.024)\end{array}$ \\
\hline Log yearly wage income (divided by 100 ) & & $\begin{array}{c}6.410 * * \\
(2.795)\end{array}$ & & $\begin{array}{c}6.687 * * * \\
(2.274)\end{array}$ \\
\hline Number of years contributed to the pension fund (divided by 100) & & $\begin{array}{c}-0.563 * * * \\
(0.103)\end{array}$ & & $\begin{array}{c}-0.098 \\
(0.085)\end{array}$ \\
\hline Pension rights at other pension funds & & $\begin{array}{l}0.035^{*} \\
(0.020)\end{array}$ & & $\begin{array}{c}0.020 \\
(0.016)\end{array}$ \\
\hline Partner has pension or income & & $\begin{array}{l}-0.008 \\
(0.015)\end{array}$ & & $\begin{array}{c}0.011 \\
(0.010)\end{array}$ \\
\hline Net housing wealth & & $\begin{array}{c}0.020 \\
(0.015)\end{array}$ & & $\begin{array}{l}0.020^{*} \\
(0.011)\end{array}$ \\
\hline Inheritance & & $\begin{array}{c}0.045^{* *} \\
(0.019)\end{array}$ & & $\begin{array}{c}0.050^{* * *} \\
(0.013)\end{array}$ \\
\hline Missing info on other pension & & $\begin{array}{c}0.090^{* * *} \\
(0.029)\end{array}$ & & $\begin{array}{c}0.361 * * * \\
(0.040)\end{array}$ \\
\hline Partner info missing & & $\begin{array}{c}-0.040 \\
(0.031)\end{array}$ & & $\begin{array}{c}-0.005 \\
(0.050)\end{array}$ \\
\hline Net housing wealth missing & & $\begin{array}{c}0.001 \\
(0.030)\end{array}$ & & $\begin{array}{c}0.233^{* * *} \\
(0.046)\end{array}$ \\
\hline Info on inheritance missing & & $\begin{array}{c}0.070 * * * \\
(0.025)\end{array}$ & & $\begin{array}{c}0.408^{* * * *} \\
(0.035)\end{array}$ \\
\hline Self-reported general health & & $\begin{array}{l}-0.003 \\
(0.010)\end{array}$ & & $\begin{array}{c}0.003 \\
(0.008)\end{array}$ \\
\hline Self-reported work limitations & & $\begin{array}{c}-0.002 \\
(0.020)\end{array}$ & & $\begin{array}{c}0.025 \\
(0.016)\end{array}$ \\
\hline Number of doctor visits in past year & & $\begin{array}{c}0.002 \\
(0.003)\end{array}$ & & $\begin{array}{c}-0.002 \\
(0.002)\end{array}$ \\
\hline Sick for $>14$ days in past year & & $\begin{array}{c}0.018 \\
(0.019)\end{array}$ & & $\begin{array}{c}-0.005 \\
(0.015)\end{array}$ \\
\hline Constant & $\begin{array}{c}0.226^{* * *} \\
(0.009)\end{array}$ & $\begin{array}{l}-0.189 \\
(0.373)\end{array}$ & $\begin{array}{c}0.064 * * * \\
(0.006)\end{array}$ & $\begin{array}{l}-0.467 \\
(0.302)\end{array}$ \\
\hline Observations & 5,360 & 4,870 & 5,488 & 3,489 \\
\hline $\begin{array}{l}\text { R-squared } \\
* * * p<0.01, * * p<0.05, * p<0.1 \text {. Standard errors in parentheses }\end{array}$ & 0.003 & 0.035 & 0.021 & 0.197 \\
\hline
\end{tabular}


Table 6 Do people change their retirement expectations?

Expected retirement age Late retirement (expected Expected retirement age 5

\section{VARIABLES}

Treated (affected by the policy)

Age (in days divided by 100)

Married

Lower secondary education

Higher secondary education

Higher education

Government

Education sector

Energy, public transportation

Physically demanding work

Mentally demanding work

Fraction of non-routine tasks

Log yearly wage income (divided by 100)

\# of years contributed to the pension fund (/ 100)

Pension rights at other pension funds

Partner has pension or income

Net housing wealth

Inheritance

Missing info on other pension

Partner info missing

Net housing wealth missing

Info on inheritance missing

Self-reported general health

Self-reported work limitations

Number of doctor visits in past year

Sick for $>14$ days in past year

Constant

Observations

R-squared

$* * * p<0.01, * * p<0.05, * p<0.1$. Standard errors in parentheses $\begin{array}{cr}\text { ate retirement }(\text { expected } & \text { Expected retirement } \\ \text { retirement age }>63) & \text { years ago }\end{array}$

III IV

$0.030^{* * *} \quad 0.156^{* *}$

(0.004)

(0.026)

0.002

$(0.006)$

$-0.032$

$(0.024)$

$-0.050^{* *}$

$(0.025)$

$-0.013$

(0.036)

$-0.026$

$(0.022)$

$-0.040$

$(0.038)$

$-0.022$

(0.039)

$-0.093 * *$

$(0.041)$

$-0.008$

(0.022)

$-0.049 * * *$

(0.014)

$0.112 * * *$

(0.032)

$-1.589$

(2.929)

$-0.859 * * *$

(0.108)

$-0.001$

$(0.021)$

$-0.005$

$(0.015)$

-0.031 *

(0.016)

0.013

$(0.020)$

$-0.048$

$(0.030)$

$-0.022$

(0.033)

0.004

(0.031)

0.014

(0.026)

$-0.024 * *$

(0.011)

$-0.064 * * *$

(0.021)

0.002

(0.003)

0.004

$(0.020)$

$0.778^{* *}$

(0.390)

4877

0.063

$\mathrm{V}$ years ago $\mathrm{V}$

$\begin{array}{ll}-0.080 & -0.139\end{array}$

(0.064) (0.130)

0.004

(0.031)

$-0.445^{* * *}$

(0.124)

$-0.259 * *$

(0.128)

0.106

(0.179)

$0.236^{* *}$

(0.114)

$-0.483 * *$

(0.193)

$-0.052$

(0.198)

$-0.729 * * *$

(0.222)

$-0.052$

(0.113)

$-0.278^{* * *}$

(0.073)

$0.581^{* * *}$

(0.163)

$41.410^{* * *}$

(15.501)

$-6.821 * * *$

(0.559)

0.015

(0.105)

0.092

$(0.075)$

$-0.083$

(0.078)

0.099

(0.095)

$-0.091$

$(0.148)$

0.152

(0.166)

$-0.048$

$(0.158)$

$-0.148$

(0.126)

$-0.188^{* * *}$

(0.056)

$-0.297 * * *$

$(0.107)$

0.003

$(0.015)$

0.004

(0.103)

$61.497 * * * \quad 60.052 * * *$

(0.047) (2.049)

$4853 \quad 4323$

$0.000 \quad 0.092$ 
Table 7 The importance of the reform, retirement expectations and savings behavior VARIABLES

Treated (affected by the policy)

I

$0.031 * *$

$(0.013)$

$-0.002$

Expected retirement age

(0.001)

Expected late retirement

$\begin{array}{cc} & -0.005 \\ 0.000 & (0.007) \\ (0.008) & -0.000 \\ 0.015 & (0.008) \\ (0.012) & 0.015 \\ 0.108 & (0.012) \\ (0.221) & -0.035 \\ 3,336 & (0.205) \\ 0.110 & 3,336 \\ & 0.111\end{array}$

Extra pension savings

Life course savings

(0.008)

II

$0.031 * *$

(0.013)

Constant

Observations

R-squared

0.110

0.111

$* * * p<0.01, * * p<0.05, * p<0.1$. Standard errors in parentheses

The regressions include the same set of regressors as in specification IV of Table 2 (a set of health variables, individual and job characteristics and selected wealth variables). 
Figure 1: Validity of the natural experiment: Does the population understand the reform?

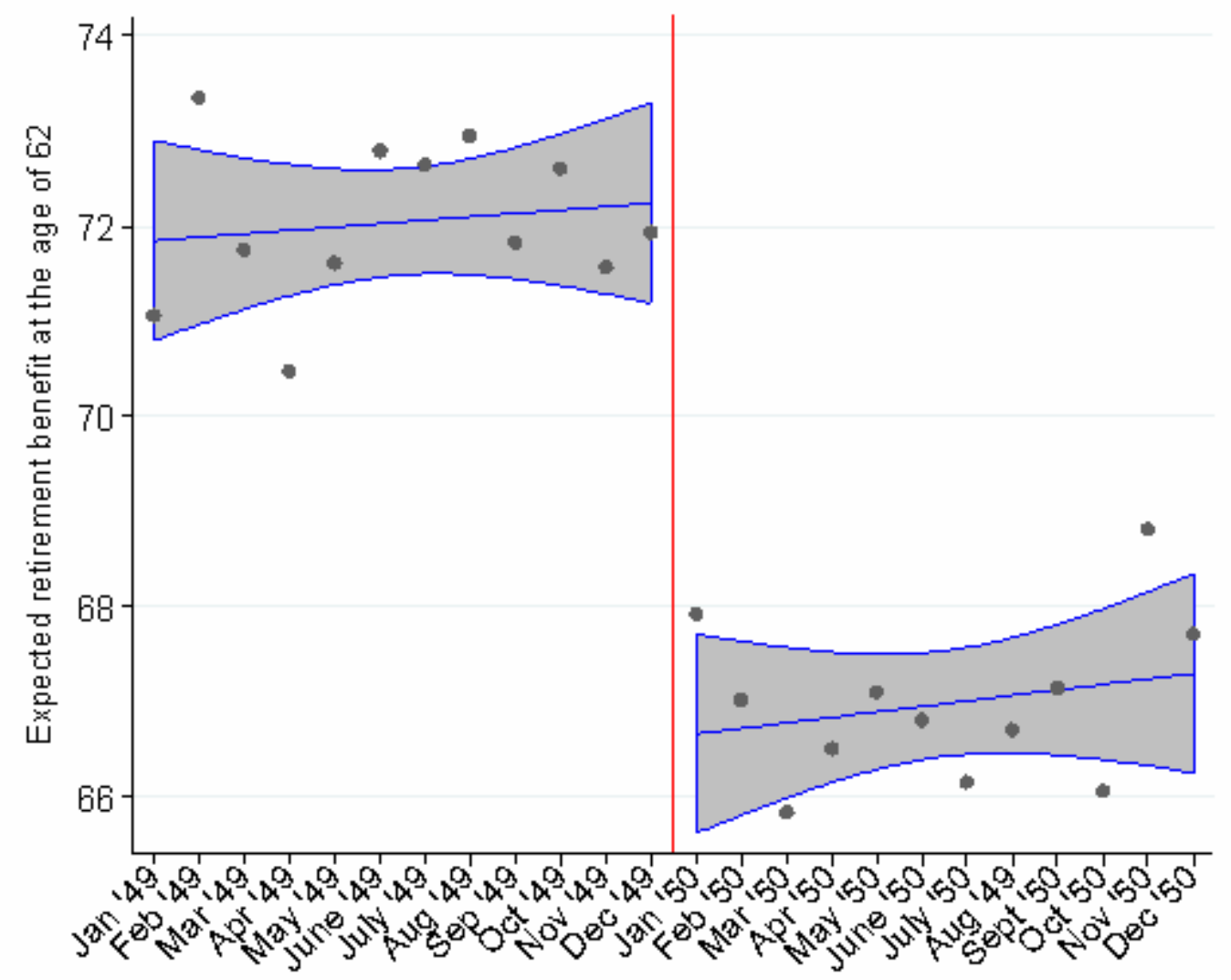

Birth month

This figure presents the mean expected pension benefit at age 62 in percentage of present wage income for each birth month. The information is based on the following survey question: "Suppose you would retire at the age of 62 . How large would your pension benefit be (in percentage of your net wage income)?" Our sample consists of two birth years where employees born in 1949 (month 1-12) are entitled to the old pension rules and employees born in 1950 (month 13-24) are subject to the new pension rules. The vertical line in the figure marks the threshold dividing the control and treatment groups. 
Figure 2a: Expected retirement age ("At what age do you expect to stop working completely"): Treatment group

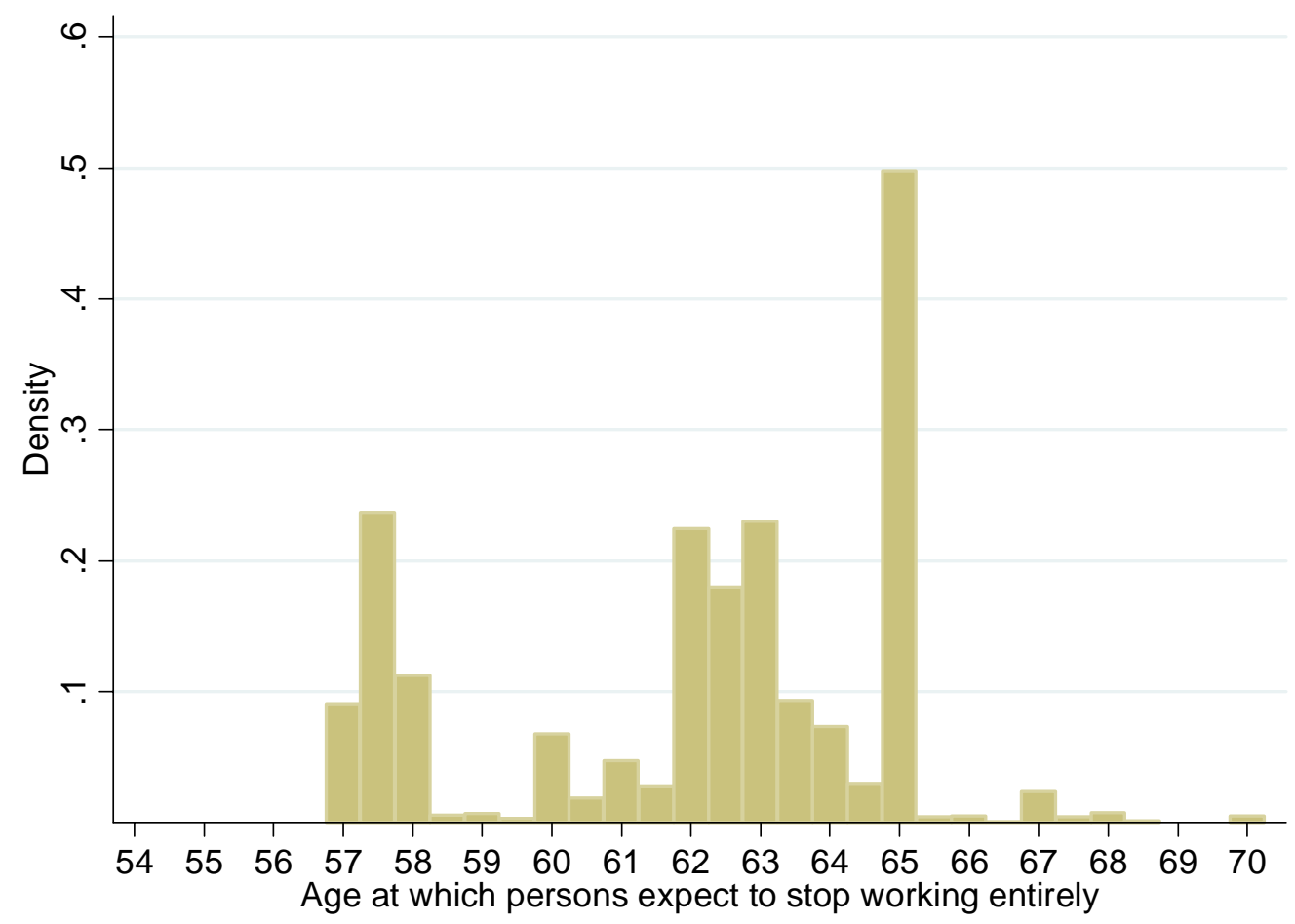

Figure 2b: Expected retirement age (“At what age do you expect to stop working completely"): Control group

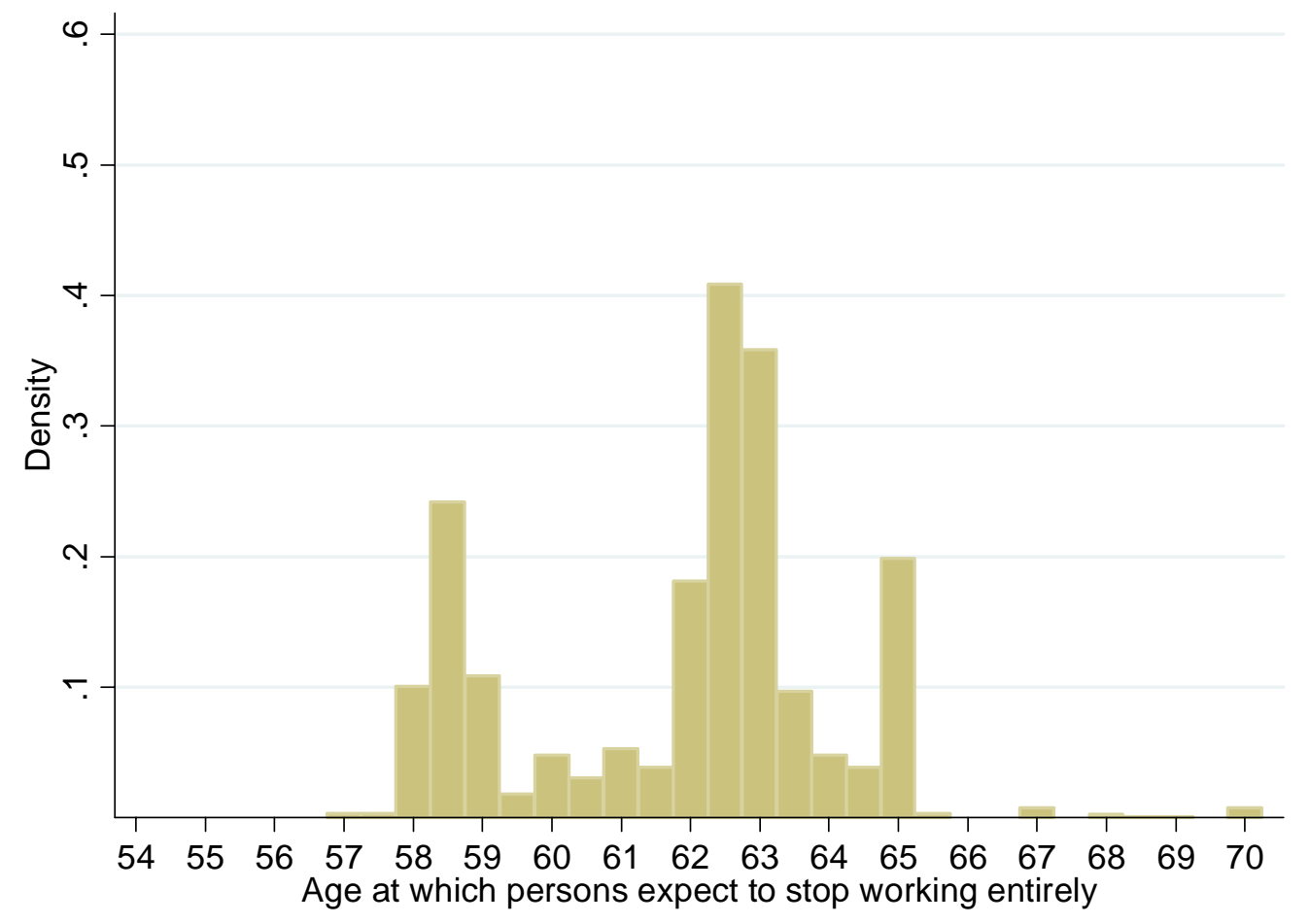


Figure 3a: Expected retirement age five years ago: Treatment group

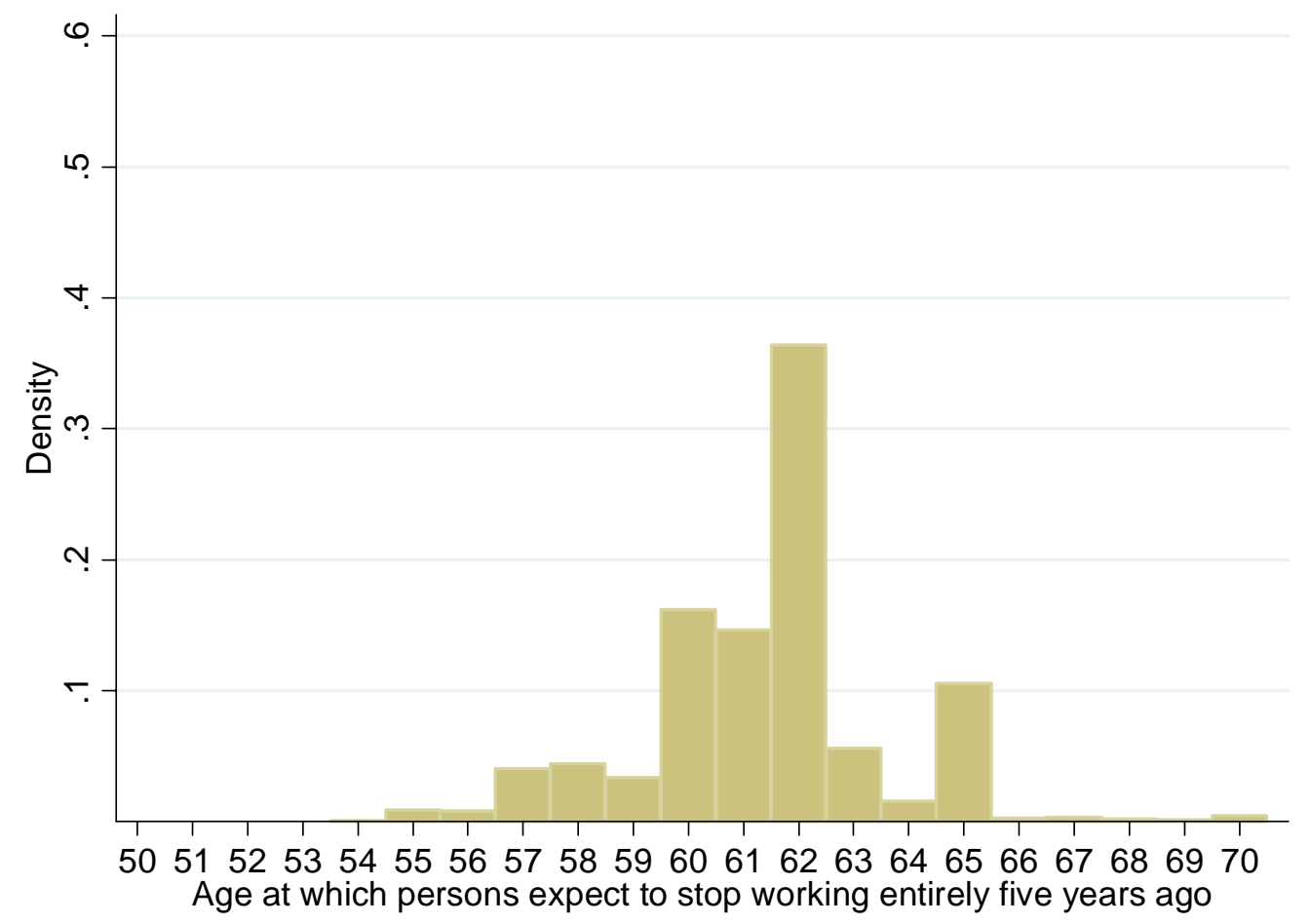

Figure 3b: Expected retirement age five years ago: Control group

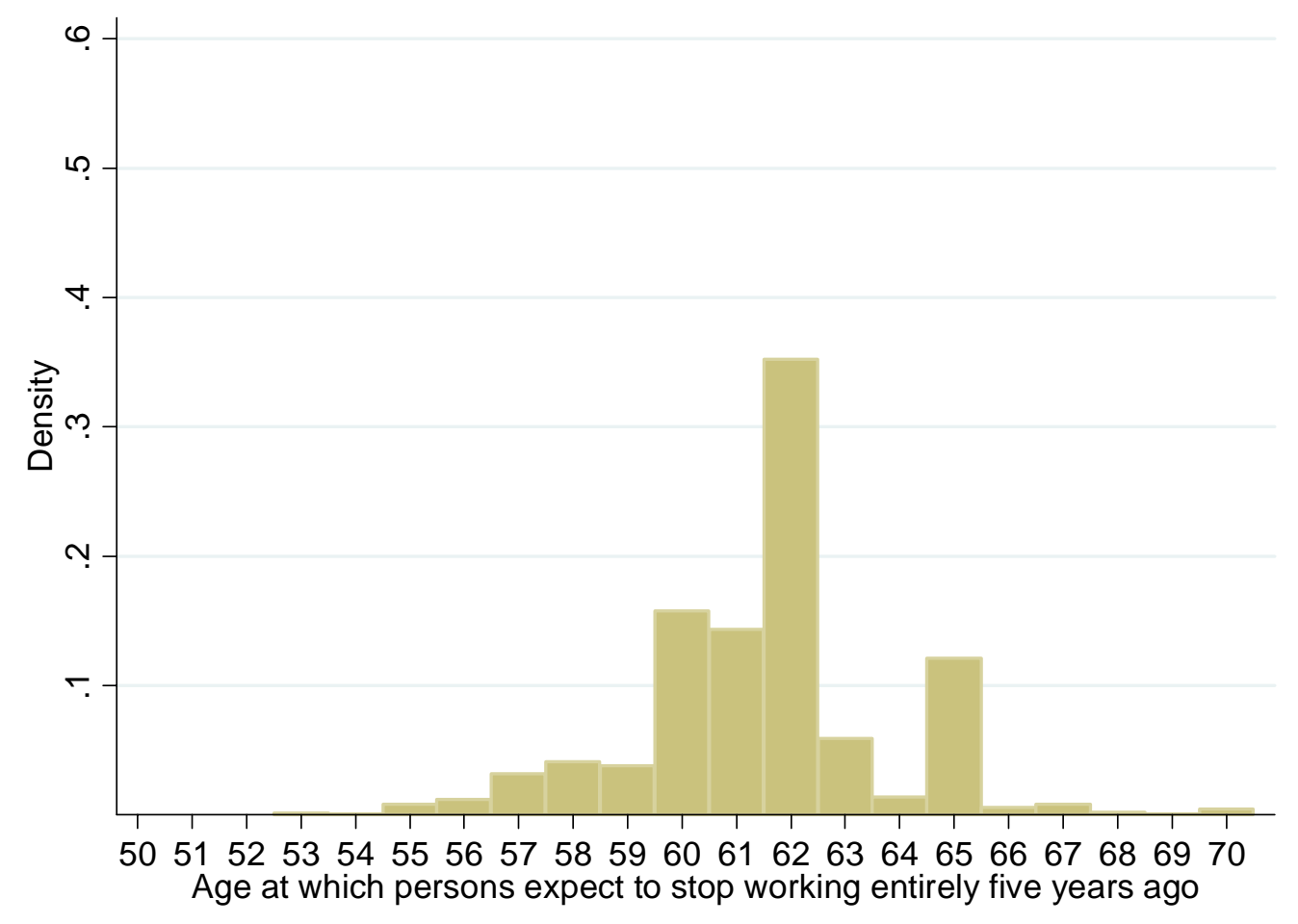




\section{Appendix}

Table A1 The effect of the policy change on mental health (Poisson regressions on CESD8 score)

VARIABLES

Treated (affected by the policy)

$\begin{array}{cc}\mathrm{I}^{1} & \mathrm{II} \\ 0.066^{* * * *} & 0.093 * * * \\ (0.021) & (0.034) \\ & 0.012 \\ & (0.008) \\ & -0.182 * *\end{array}$

Age (in days divided by 100)

$-0.182 * * *$

Married

Lower secondary education

0.017

(0.034)

Higher secondary education

0.016

(0.051)

Higher education

0.040

$(0.029)$

Government

$-0.013$

(0.055)

Education sector

$-0.007$

(0.056)

Energy, public transportation

$-0.005$

(0.059)

Physically demanding work

0.020

Mentally demanding work

(0.025)

$0.206 * * *$

(0.018)

Fraction of non-routine tasks

$-0.099 * *$

$(0.044)$

Log yearly wage income (divided by 100)

$-15.650 * * *$

(4.102)

Number of years contributed to the pension fund (divided by 100)

0.169

$(0.139)$

0.015

(0.029)

Pension rights at other pension funds

$-0.092 * * *$

(0.020)

$-0.009$

(0.021)

$-0.042$

(0.026)

Inheritance

$0.096 * *$

(0.046)

Missing info on other pension

$-0.123 * * *$

Partner info missing

$(0.035)$

Excess housing wealth missing

0.000

$(0.042)$

$-0.001$

(0.036)

$0.214 * * *$

(0.013)

$0.285 * * *$

(0.033)

$0.013 * * *$

Number of doctor visits in past year

(0.003)

$0.142 * * *$

Sick for $>14$ days in past year

(0.026)

Observations

5, 195

4,765

$* * * p<0.01, * * p<0.05, * p<0.1{ }^{1}$ The table shows marginal effects. Standard errors in parentheses. 